\title{
The hidden effects of environmental noise
}

In the modern mechanised world noise is everywhere. As professionals in otology we all know the damaging effects of excessive noise on the inner ear. What are less appreciated are the adverse health effects of long-term exposure to lower levels of environmental noise. A recent report from the World Health Organization and European Commission ${ }^{1}$ estimates the "Burden of disease from environmental noise" in terms of healthy life years lost. It is clear from the data presented that the effects of environmental noise are felt in parts of the body remote from the ear. It is estimated that disability adjusted life years (DALYs) lost from environmental noise in western Europe are 61000 years for ischaemic heart disease, 45000 years for cognitive impairment of children, 903000 years for sleep disturbance, 22000 years for tinnitus and 654000 years for annoyance. ${ }^{1}$

Although the most notable contributor to environmental noise is road traffic, an article in this issue highlights excessive noise from wind turbines. ${ }^{2}$ In particular the so-called "Wind Turbine Syndrome" is thought to include tinnitus, vertigo, migraine and sleep deprivation. The damaging effects of wind turbines have been attributed to infrasound and lowfrequency noise.

An additional article in this issue reports possible adverse effects of occupational noise exposure on central auditory pathways. Hope and colleagues ${ }^{3}$ found impaired speech-in-noise perception in subjects with normal pure tone audiograms that had been exposed to occupational noise, compared with control subjects.

\section{ROBIN YOUNGS EDWARD FISHER}

Editors

\section{References}

1 Burden of disease from environmental noise. Quantification of healthy years lost in Europe. World Health Organization (Europe Regional Office) 2011. http://www.euro.who.int/_data/assets/ pdf file/0008/136466/e94888.pdf [12 February 2013]

2 Farboud A, Crunkhorn R, Trinidade A. 'Wind turbine syndrome': fact or fiction? J Laryngol Otol 2013;127:222-6

3 Hope AJ, Luxon LM, Bamiou D-E. Effects of chronic noise exposure on speech-in-noise perception in the presence of normal audiometry. J Laryngol Otol 2013;127:233-8 